\title{
Understanding Customer Needs and Wants
}

\author{
By Mark Anthony Camilleri ${ }^{1}$, PhD (Edinburgh)
}

This is a pre-publication version of a chapter that was accepted by Springer Nature.

How to Cite: Camilleri, M. A. (2018). Understanding Customer Needs and Wants. In Travel Marketing, Tourism Economics and the Airline Product (Chapter 2, pp. 29-50). Cham, Switzerland: Springer Nature.

\begin{abstract}
Business ought to understand their customers' needs and wants, if they want to remain successful in a competitive market place. Therefore, this chapter introduces its readers to market research as tourism businesses continuously require information on their customers. In this light, a well laid-out plan will help them sharpen their research objectives. Once a research problem has been defined, an appropriate methodology could be chosen to gather exploratory or descriptive data. Very often, the tourism businesses may outsource the market research function to specialised agencies. The successful research organisation which has been entrusted with the market research will collect the data, analyse it and interpret its findings. Afterwards, the research agency will be in a position to report its conclusions, research limitations and implications of study. The research report will only add value to the commissioning business if the marketing managers would take heed of its key recommendations.
\end{abstract}

\subsection{Introduction}

The tourism service providers should have a good understanding of their customers. They are expected to continuously research the market to get to know their customers' needs and wants. This chapter raises awareness on the importance of market research for tourism businesses. It provides an outline for a research plan, which is intended as a guideline for prospective

\footnotetext{
${ }^{1}$ Department of Corporate Communication, Faculty of Media and Knowledge Sciences, University of Malta, Malta. Email: mark.a.camilleri@um.edu.mt
} 
practitioners in travel marketing. Hence, the readers of this chapter will acquire relevant knowledge on market research techniques, methodologies, data analyses and interpretation of the findings.

If the research is outsourced to a specialised agency, the business should provide a brief to the research organisation which explains its research objectives; it outlines how market and consumer data can be collected; the type of research being envisioned (by clearly indicating what are the businesses' expectations from this project); question areas to be covered during the research; it provides a realistic time table; as well as a budget. Subsequently, the agency will usually return a proposal to the business by an agreed date. It is advisable that the commissioning business will ask for quotes from several research agencies before committing itself with one of them.

\subsection{The Rationale for Market Research}

Drucker (1973) contended that the purpose of the business is to create a satisfied customer. He went on to suggest that marketing cannot be considered as a separate function, it is the whole business that is seen from the point of its final result, that is, from the customers' point of view. Kotler (1973) argued that marketing is about offering the right product or service at the right price; that is available in the right place, at the right time, and, doing so at a profit. In other words, marketing is essentially the management process by which companies identify, anticipate and satisfy their customers' need and wants, while simultaneously making a profit. In a similar vein, Levvitt (1986) held that the purpose of a business is to create and keep a customer. He maintained that there can be no corporate strategy that is not in some fundamental fashion a marketing strategy, as the purpose of business is to sell products or services that customers are willing to purchase. Therefore, if a company is truly market oriented, it will focus its attention and activities on its customers and their expectations. The actions of such a company arise directly from its customers' needs and wants.

Discussions about the purpose of marketing are still ongoing. Grönroos (2006) suggests that "Marketing is a customer focus that permeates organisational functions and processes and is geared towards making promises through value propositions, enabling the fulfilment of individual expectations created by such promises and fulfilling such expectations through support to customers' value-generating processes, thereby supporting value creation in the 
firms' as well as its customers' and other stakeholders' processes', (p. 407). Academics often refer to this belief as the marketing concept, which says that the best way for a firm to accomplish its goals over the long run is to choose a group of customers and to do a better job than competitors in satisfying the needs of those customers. To do this, a company must put itself in the customer's situation.

The marketing management process is responsible for identifying, anticipating and satisfying customer requirements, at a profit. It is the job of the marketing managers to link and sequence operational activities and to co-ordinate the work of all commercial areas. They must also work closely with other departments (including; finance, maintenance, operations, et cetera) towards the goal of adding value to the customer and to the business itself. Marketing managers must ask themselves what the real value of their products or services is to their consumers. Vargo and Lusch (2004) suggested that the marketing of travel and tourism involves the co-creation of value, as intangible, dynamic resources are more important than tangible, static resources, because of the inseparability of production and service consumption. Therefore, today's marketers are expected to anticipate their individual customers' needs and wants; to ensure their long-term value, over time. This, of course, requires extensive market research and analysis. Hence, it is imperative that companies carry out a rigorous process of customer and market analysis. It is in their interest to investigate the present market, the needs and wants of customers and how they may satisfy them. It is necessary to investigate possible competition and to anticipate market developments through market research. Market research may be defined as the systematic design, collection, analysis and reporting of data and findings relevant to a specific marketing situation facing a company (Kotler \& Armstrong, 2012). The processing and analysis of information obtained through market research provides them with relevant knowledge base on which they can make better decisions about the development of a product or a service. The knowledge generated through marketing research is therefore classified into the content areas of making, enabling or keeping a promise.

\subsection{Assessing the Customers' Needs and Wants}

Basically, a need is a conscious feeling of deprivation in a person. In other words, it is something which a customer requires to experience satisfaction. For example, in the case of business travellers, the punctuality of a service is a good example of what constitutes a need 
(Peterson, Neels, Barczi \& Graham, 2013). An airline failing to provide a high standard of punctuality will lose business to its competitors. For example, the travel search engines analyse and profile hotels to refine their offerings to online users. Many prospects search for accommodation in specific areas (for example in the city centre). They may expect to have breakfast, wifi or internet access, a fitness centre and car parking facilities in their hotel. They may demand for accessible rooms as they may have a reduced mobility. The online booking site convert these requests into meaningful results, as it shows the right hotels which match the criteria of prospective guests.

However, not every customer requirement can be put under the heading of a need. For example, a warm and friendly attitude on the part of the cabin staff, though pleasant, cannot be said to have a crucial influence on the traveller's choice of an airline. It should therefore be classified as a want rather than a need. Wants are highly significant in marketing today because, in many markets, airlines can meet customer needs just as well as their competitors. On many routes, passengers fly similar aircraft, and could notice that several airlines offer similar time tables and punctuality records. In such situations, the customers' choice of airline is frequently based on less significant wants.

A want is a need after it has been influenced by culture, society and an individual's personality. There are two kinds of wants, a 'tangible' want and a 'psychological' want. For instance, the business travellers appreciate the product feature of a separate class of service, on-board an aircraft. The costly option of travelling in separate, dedicated cabins provide business passengers with a peaceful environment away from crying children, where they can rest or work. Of course, there are other needs and wants for different types of travellers:

The needs of the short-haul traveller include the high frequency of service from a convenient local airport, suitable flight timings, high standards of punctuality, a totally flexible product in terms of seat accessibility, ease of cancellation and rebooking and the ability to "no-show" without penalty, among others. In the case of business travellers, price is not on necessarily on their top list of priorities.

In looking at the wants of a short-haul traveller, it is important to recognise the difference between independent and corporate business travellers. The independent travellers will generally accept product frills only if they are offered at no extra charge. The corporate travellers are usually attracted to airlines offering frills, before and during the flight. 
Attractive product frills include separate check-in desks for business travellers before their flight, luxurious lounge facilities, the provision of a separate business class cabin, comfortable seating with adequate legroom as well as gourmet meals on board the aircraft, among other aspects of service. Moreover, all passengers expect efficient baggage handling and a high level of customer service in every encounter with airline employees.

In addition to the needs and wants of the short-haul travellers, long-haul travellers may demand a non-stop service to their chosen destination. Inflight entertainment facilities are also expected to reduce the tedious nature of travelling for long hours. Moreover, on long-haul flights, the business traveller will require comfortable seating and leg room, as well as substantial meals.

Price is by far the most influential factor in the choice of airline transportation for a high proportion of leisure passengers. Leisure travellers pay for their flight from their own pocket. If the air fares are too expensive, family groups will not afford holidays. Of course, leisure travellers' needs may be similar to those of the business travellers, but their demands may be far less rigorous, as they paid considerably less money for their tickets.

Both business and leisure travellers will expect airlines to assure them of their safety and security. This issue will surely be on their list of concerns. A substantial amount of leisure travellers may include apprehensive holiday goers who do not fly on a regular basis. Another aspect which is important to the leisure traveller is the availability of peak-time capacity. Generally, such peaks occur during the weekends and on a seasonal basis, due to holiday scheduling from work. It is important that the airlines allocate sufficient capacity to meet the demand at such peak times. Notwithstanding, a pleasurable inflight service is also very much appreciated by leisure travellers.

Indeed, there is potential for airlines to operate successfully and at a profit, if they anticipate their customers' needs, wants and expectations. Amid incidents like the recent United Airlines overbooking debacle or Delta's spring break computer outage that may have tainted the respective airlines' reputation and image, an American Customer Satisfaction Index (ACSI), that was conducted between April 2016 and March 2017, indicated that passengers were satisfied (with an ACSI score of 75\%) with the levels of airline service. However, United's violent removal of a passenger was captured on social media, but is not reflected in the ACSI results as it occurred after the completion of data collection. United's incident did cause a fall in the company's stock price. For the time being, it is still unclear how much impact this specific 
incident will have on future passenger satisfaction as United already has the lowest score among the full-service, legacy airlines. Industry leaders, including; JetBlue scored 82\%, Southwest $80 \%$, and Alaska Airlines $78 \%$ were among those successful airlines, according to ACSI. Very often other carriers, including legacy airlines are falling behind in terms of customer satisfaction. Yet, the most dissatisfied passengers are those who are only opting for low-price above anything else. In this case, the ultra-low-cost operators Spirit and Frontier were among those airlines who have mostly suffered from a reduction in customer satisfaction, when compared other airlines (ACSI, 2017).

Major airlines like Delta and American are increasingly competing more aggressively on price. However, although they may offer low ticket prices; they cannot afford to deliver a low-quality service. According to ACSI, in the last three years, Spirit has consistently ranked last in terms of passenger satisfaction, although the airline did improve last year (up from 54\% in 2015 to $62 \%$ in 2016). However, the airline did not build upon its gains in 2017. Spirit's efforts to improve customer relations and punctuality did not pay off, as yet, as their passenger satisfaction currently stands is $61 \%$.

In a similar vein, in 2016, guest satisfaction with hotels was 76\%, according to ACSI, this score was $2.7 \%$ higher than the previous year. This growth was driven by gains for smaller hotels and bed and breakfasts (B\&Bs). Evidently, with the rise of online hospitality brokers, like Airbnb; travellers had more choices than ever before, forcing hotel operators to compete on both price and customer service.

Hilton guests were the most satisfied (81\%), and in the second place, Hyatt and Marriott scored $80 \%$. Marriott's Starwood brand came third (79\%), closely followed by InterContinental (78\%). Best Western, La Quinta and Choice that were in the range of $76 \%$ to $74 \%$; while the combined score of all other smaller hotels and B\&Bs were up by $3 \%$ to $74 \%$. Wyndham (71\%) lagged behind most of the major hoteliers, but G6 Hospitality (Motel 6) was ranked in the last place (65\%). These results indicated that many prestige hotel brands, including JW Marriott were topping the charts (85\%), while upscale Hilton Garden Inn and Hyatt Place have shared the next spot at $84 \%$. Starwood's Aloft, part of the Marriott family, scored 83\%, alongside Hilton's Embassy Suites Hotels. With 76\%, Wyndham Baymont Inn \& Suites was top-rated among midscale properties, whist Days Inn (67\%) was the best economy brand. However, Super 8 from the Wyndham family had the lowest-ranked chain in the industry, at $63 \%$. 
The customer satisfaction levels with travel websites for booking flights, hotels and car rentals stood steady at $79 \%$. Expedia gained $4 \%$, as it rose to $80 \%$. Other brands of the Expedia family, Orbitz also gained $1 \%$ to $78 \%$. Whilst Travelocity lost $1 \%$ to $77 \%$, which is in line with its competitor Priceline (77\%), which lost 5\% from the last year's score. These ACSI (2017) reports were based on the findings from 8,660 customer surveys that were duly collected between April 18, 2016, and March 19, 2017.

\subsection{The Marketing Research Process}

Marketing managers could use research data to personalise their products or services to their customers. For instance, the customers (or guests) of a hotel could have their own needs and wants. The hotel guests may be leisure travellers, including families with children, senior citizens, young adults, et cetera. Alternatively, they may comprise business travellers who travel on their own. Therefore, relevant market research will provide the hotel management with a good insight on their guests, and their preferences. This information will support hotels' front liners in delivering an appropriate customer service to their guests. This way, they could be in a position to improve their guests' customer experience.

There are a variety of market research techniques which may be applied by travel marketers, for example, survey questionnaires, interviews, focus groups and so on (Bryman, 2006, Patton, 1990). Quantitative research involves the statistical analysis of large numbers of people, or a representative sample of them (Creswell \& Clark, 2007). Generally, this latter form of research is conducted in a highly structured way. The quantitative research may also be conducted through the use of scales, (for example, by using Likert and / or Semantic Differential Scales) in questionnaires. This research technique uses parameters such as population shape, size, proportions, and so on. It entails sampling, questionnaire construction, interviewing and data processing, by using statistical formulae. The qualitative research involves the collection of a significant amount of data from a relatively small sample of informants, as opposed to quantitative research.

However, irrespective of the type of research technique which you apply, there are certain stages in the market research process which must be carried out, as illustrated in Figure 2.1: 
Figure 2.1 The Market Research Process

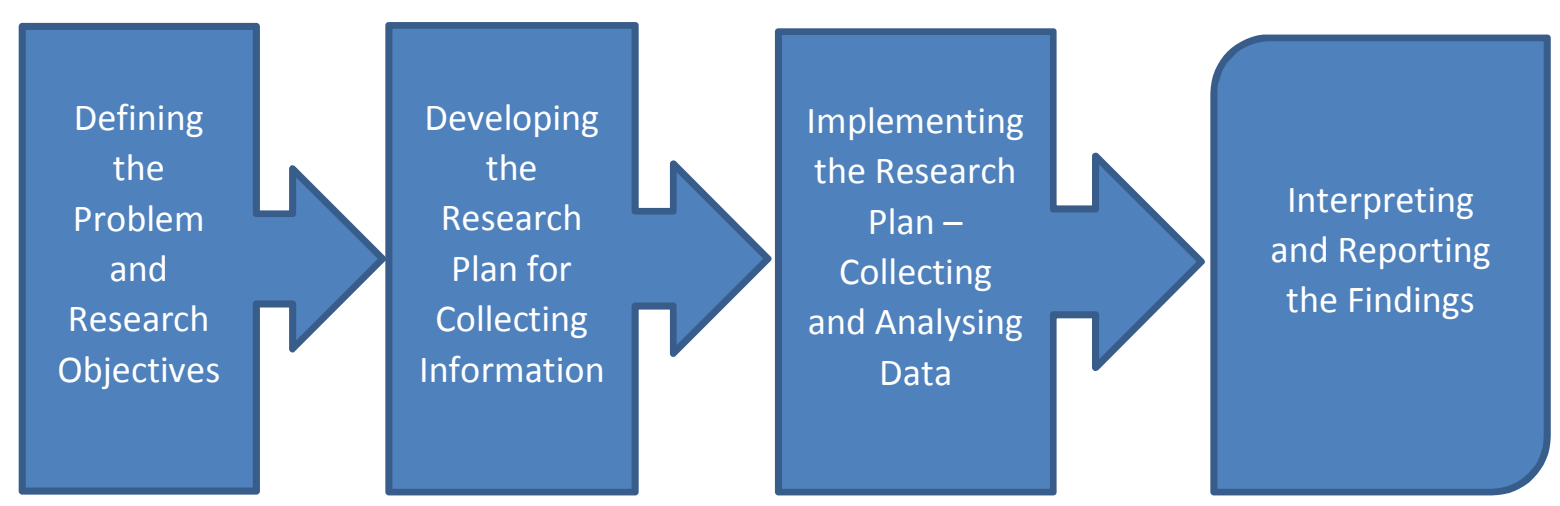

\subsection{Defining the Problem and the Research Objectives}

This is the initial stage of the research process. It involves identifying the research problem and carefully defining the research objectives. The market researchers should also decide what form of information they require. Basically, there are two forms of research objectives:

- Exploratory: This type of research gives an insight on problems that are in a preliminary stage of investigation. Exploratory research help the marketer to better define the problem, and to define a hypothesis;

- Descriptive: This type of research is used to describe the characteristics of a population or phenomenon being studied. It does not answer questions about how / when / why the characteristics occur. Descriptive research could reveal information on the market potential, demographics, consumer attitudes, and so on. It allows researchers to test a hypothesis about cause and effect relationships.

\subsection{Designing the Research Plan}

Once the problem and research objectives have been defined, the next step is to concentrate on designing the research plan. This entails: 
a. Specifying the type of data to be collected and the sources from which they may be collected;

b. Determining the methods to be used for data collection (quantitative or qualitative research techniques);

c. Deciding whether to use random or non-random samples;

d. Calculating the time and cost of research.

The researcher may collect primary and / or secondary data. Primary data consists of information which is not presently available, but is needed to deal with the problem under investigation. Secondary data is existing data which may be used for the problem at hand, although it was not originally gathered for this purpose. Secondary data may be gathered from internal sources (for example, booking data, fare type analysis and so on) or from external sources (data compiled by government sources, airport authorities, consultant reports, chamber of commerce reports, among others).

\subsubsection{Market Research Techniques}

There are a number of market research techniques which may be used for data collection purposes. The following is a brief account of the various types of research:

\subsubsection{Survey Questionnaires}

A questionnaire allows the researcher to gather information with a considerable level of accuracy and at an affordable cost. It is a vital element of marketing research and should be skilfully and intelligently constructed. Quantitative data can be gathered through the use of electronic, mail-based or personal, face-to-face surveys. To carry out an effective investigation, the following design criteria should be applied when creating a questionnaire:

i. To maintain the respondents' cooperation and involvement, the questionnaire must be interesting and easy to read. This may be achieved by keeping the questions as brief and concise as possible.

ii. When designing the questions the researchers should think carefully about the information they are seeking. The meaning of the questions that are asked should elicit specific information that is sought by the researchers. If a question runs over 20 words, it needs to be refined, or broken down in smaller questions. 
iii. The researchers should ensure that they ask one question at a time, and that each question can be answered in its own right.

iv. The researchers should communicate with the respondent. Questions should be clear and easy to understand. They should avoid ambiguous words and phrases, i.e. words with two or more accepted meanings. Abstract and vague concepts must be avoided. Imprecise wording can lead to confusion as well as ambiguous responses. Researchers should not formulate questions in such a way that may subject to different interpretations, as they may have more than one meaning.

v. It is extremely, important that the wording that is used in the questionnaire will be clearly understood by the participants to whom the survey is directed. Jargon or technical terms that are peculiar to a particular trade or profession must be avoided.

vi. Researchers should avoid bias. Their questions should not influence their participants' answer in any way.

vii. The participants should be helped as much as possible to work out their answers. A certain amount of generalisation should be allowed. The researchers could use prompt cards and tick boxes, as a means of enhancing the participants' memory.

viii. The sequence of the questions has a major influence on the accuracy of the gathered data. The questionnaire could be sequenced in such manner to maintain the respondents' interest and to entice them to answer all questions. The tedious questions could be placed among those which are the most interesting. Personal questions should be positioned in the latter part of the questionnaire. As a means of encouraging the respondents to answer personal questions, ask them to indicate their answer from a range of tick boxes, rather than conveying the information verbally. This may avoid any possible embarrassment and discomfort.

ix. To elicit responses to personal questions, the participants could indicate ranges, through the use of Likert scales.

Multiple choice questions may also be used. In this case, respondents are able to choose from a range of possible answers, which are designed to reflect different shades of opinions or perceptions on products or services. It is important to think carefully when designing these questions so as ensure that there are alternatives answers in multiple-choice questions. This will provide sufficient scope for respondents to make valid answers. Alternatives must be mutually exclusive (there should be only one possible answer) so that respondents are able to differentiate between responses without difficulty. 
The researchers should facilitate the interviewers' tasks by using a clear layout, large, legible type and as simple a structure as possible. To minimise costs and time, they are expected to provide an efficient basis for data processing by using specific programmes which allow them to transfer data for subsequent analysis (e.g. SPSS or STATA). The individuals' attitudes or beliefs are often very difficult to measure. However, there are effective ways in which questionnaire designs can reduce such problems. Moving scales could provide information which are easy to measure and process. For instance, the survey responses can be measured by using systematic differential scales or Likert scales from 1 to 5,1 to 7 , or 1 to 10 .

Once the questionnaire has been successfully complete, it's time to test it. Irrespective of how experienced a researcher is, or how strictly they have applied the construction rules, it is important to pilot test the questionnaire. Only by trying out the format on a small sample, the researcher will be able to assess that the questionnaire has succeeded in reaching its underlying objectives. It is at this stage that the problems of ambiguity, incomprehension and excess length can be identified and rectified in a considerably lower cost, rather than if they remain undetected, following completion of the survey.

Whether the questionnaire has been designed by the staff within your organisation or by a specialised research agency, the individual for whom the research is being conducted should insist on vetting the questionnaire. A checklist for vetting the questionnaire is suggested hereunder, in Table 2.1: 


\section{Table 2.1 Questionnaire Checklist:}

Are the research objectives right?

Are the research questions meeting these objectives?

Will the questions listed collect all the data required?

Is every question essential?

Is the right type of data collected: Are you collecting facts? opinions? motives?

Is the question sequence presented in a logical pattern?

Are the types of questions that are being used appropriate: Are you using Open-ended Questions? Multiple-choice Questions? Rating Scales?

Is the question wording simple to understand? Unambiguous? Clear?

Is it reasonable to expect the respondent to answer every question?

Will the answers be easy to record?

Will the answers be easy to process?

Does the questionnaire look good?

Is the questionnaire easy to administer?

Has the questionnaire been piloted?

Is the right type of questionnaire being used? Personal? Postal? Email? Telephone?

This research method could be an easy way to reach a large number of users and non-users of tourism products. The respondent may be more open and truthful when answering questions in the absence of interviewers (in the case of electronic or mail-based surveys). The electronic questionnaire is an inexpensive and flexible way to collect quantitative data. Survey questions must be extremely simple and clear in order to trigger high response rates. In fact, one of the main disadvantages in using this research technique is that the response rate to surveys is generally poor. Many consumers are increasingly receiving surveys through emails on a regular basis, so they may lose interest in responding to them. Very often, they ignore them or simply forget to complete them. 


\subsubsection{Inflight Survey}

The inflight survey is a commonly used method of data collection in the aviation industry. As the name suggests, this form of research is carried out during the flight. It is aimed at establishing the customers' feelings toward product specification, for example; seating comfort, meal quality and other airline features.

However, there are some disadvantages that are related to this research technique. It is extremely difficult to obtain a random sample of respondents, although all inflight passengers may have an equal chance of being included in the survey. The researcher must rely on the cabin crew to distribute the questionnaires. However, the cabin crew may not be objective spectators. Should they suspect complaints and negative feedback from specific travellers, they may be tempted to overlook them when distributing the questionnaire or to reject the completed surveys which will have negative criticism. Due to the time-constraints of a short-haul journey, the inflight questionnaire may only be given on preselected seat numbers, which may be allocated on a random number basis. This may also result in bias. On long-haul flights, such bias is reduced, as there is sufficient time for all passengers to receive and complete the questionnaires, before landing.

Again, questionnaires must be short, specific and direct (as explained above). Due to time constraints and other factors, there may be no room for open-ended questions. As a result, it is very difficult to collect general attitudes and opinions; which could prove useful to making strategic marketing decisions on responses that are based on multiple choice questions or scales. Therefore, marketing managers should also give due consideration to open-ended questions to ensure that they obtain the information they are seeking (although participants may not always provide their feedback, as it is easier for them to complete multiple choice answers). It is important to use open-ended questions in an effective and intelligent manner.

The main problem with inflight surveys is that the research participants have deliberative chosen to travel with your airline. Although, their feedback is useful, it is really those passengers who are travelling with competitors who should be questioned. 


\subsubsection{Face-to-Face Interviews and Focus Group Meetings}

Qualitative research is usually conducted in a fairly, unstructured way, usually through in-depth interviews or through focus group meetings. In this case, the researcher explores the informants' reactions, opinions and behaviours of a small number of individuals; which are known as the sample of the population. Due to the small scale of the investigation, qualitative research is usually completed more quickly than quantitative research.

However, in this case, the collected data cannot be justified in statistical terms. Even though the research findings may give clues about other members of the target population, the data base is too small to make generalised statements like; "10\% of the target population believe that...". The findings from this form of research may give an insight into existing trends. The qualitative methods could enable researchers to continue their investigation through quantitative research.

Qualitative data may be gathered from individuals or by forming focus group discussions amongst selected customers. However, the latter form of qualitative research is timeconsuming, logistically difficult and quite costly. If the interviewers are highly-skilled, and the methods they use are reliable; personal interviewing is a flexible way of gathering relevant information concerning; consumer perceptions, and opinions. Such qualitative data will enable the business to make sound decisions in relation to the introduction of new products and to ascertain the consumers' attitudes toward existing services. It will also provide them with the opportunity to shed light on any problems and difficulties which the company may be experiencing at a particular point in time.

\subsubsection{Telephone Interviews}

Telephone interviewing is a good way of accessing research participants. However, it is often perceived as an invasion of privacy; which may result in tarnishing the corporate image of the business. Moreover, there may be difficulties in contacting the selected respondents, as their contact numbers (land lines or mobile phones) may not be listed.

\subsubsection{Test Marketing}

Test marketing is a remarkably versatile marketing tool. For example, a particular business is considering launching a new product or it may introduce a new service. It would be more 
feasible for the business to test its innovation for a short period of time before introducing a product or changing its established services. The first reaction from customers experiencing this new product is usually recorded through questionnaires that are subsequently analysed and interpreted by researchers. This enables marketers to decide whether they should modify their products before fully implementing them (Shaw, 2016). Although test marketing is a reliable way of assessing the customers' reactions, it does not always guarantee success. Management must still make important decisions. However, after the market research, their decisions will be more informed as they could be based on the consumers' reactions to their products or services.

Test marketing can be a costly exercise and may lead to confusion among travellers, particularly if new product features are discontinued at the end of the testing period.

\subsubsection{Complaints and Complaint Analysis}

This research technique is a very valuable and simple indication of customer dissatisfaction on the businesses' existing products or services. A consistently, high frequency of complaints is a clear indication of customer dissent on certain aspects of the business. The marketing managers ought to be proactive on consumer complaints and should immediately act on improving their weaknesses. A system for classifying complaints and complements must be operated by the respective businesses before such a research technique may be implemented.

\subsubsection{Customer Contact Staff}

Another important source of qualitative information that is readily available to the businesses is from their own sales and customer service employees. These people are in touch with the customers. They are in a valuable position to provide first-hand information about customers' feelings toward various products and services.

\subsubsection{Desk Research}

Desk research is another important technique for data collection. It involves the analysis and interpretation of already available data. Businesses may collect data from both internal and external sources. Although this form of secondary research is very practical as it is relatively cheap and fast; the gathered data may not always be in an ideal form. The data collected from external sources may be out-of-date by the time it is published. Moreover, it would be more 
advisable for the businesses to carry out their own research, on a regular basis; as there may be frequent changes in the marketing environment.

\subsubsection{Sampling}

Sampling is one of the major tools of market research. It involves the study in considerable detail, of a relatively small number of informants who have been selected from a larger group. To carry out successful market research, it is important to have a clear understanding of what sampling is all about. Here are some important terms which are used in the realms of research:

Population: This refers to any group or objects which are alike in one or more ways, and which form the subject which is being studied in the survey. In certain cases, human populations can refer to special sections of the general population of a country; for example, business travellers who have flown to a particular route and so on. It is necessary to clearly define the population before starting the data gathering process.

A Census: This occurs when a universe is being investigated in its entirety. This rarely happens in commercial research, unless the universe is small and is easily located.

A Sample: This may be defined as a segment of the population. It is a microcosm of the population from which it is drawn so that conclusions made about a particular sample can be extended to the population it represents. Sampling selection techniques seek to ensure that the members of a survey sample are truly representative of the members of the population from which they are chosen. A sample cannot reflect a completely perfect image of the population. However, distortion can be minimised if careful attention is paid to the principles which must be applied when sampling. Without correct sampling procedures, the sample selected would not be representative, and the research findings would not be valid and reliable. Samples are used in all types of marketing, from ad hoc product tests to continuous surveys, such as the measurement of television audiences.

The Sampling Frame is the source material or device from which a sample is drawn. It is a list of all those within a population who can be sampled, and may include individuals, households or institutions.

Probability Sampling or Random Sampling: This sampling technique will consider every member of the population, as all individuals will have an equal chance of being included in the 
sample. The first step in drawing a random sample is to make a list of all members of the population. The probability of getting any particular sample may be calculated.

In a simple random sample, each research participant is chosen at random, such that each individual has the same probability of being chosen, at any stage during the sampling process. The simple random sample is an unbiased surveying technique. Systematic sampling is a statistical method involving the selection of elements from an ordered sampling frame. The most common form of systematic sampling is the equi-probability method.

Stratified Sampling: This technique suggests that the sub-populations (strata) could be sampled, independently. Stratification is the process of dividing members of the population into homogeneous sub-groups, before sampling. The strata should be mutually-exclusive: every element in the population must be assigned to only one stratum. The strata should also be collectively-exhaustive: no population element can be excluded. Then simple random sampling or systematic sampling is applied within each stratum. This often improves the representativeness of the sample by reducing sampling error.

Nonprobability sampling techniques are not intended to be used to infer from the sample to the general population, in statistical terms. The chosen sample does not represent the whole population. However, non-probability sampling is widely used in qualitative research. Examples of nonprobability sampling include:

- Convenience sampling: The research participants are chosen due their relative ease of access. Such sampling is biased because researchers may unconsciously approach certain respondents and avoid others. Moreover, there may be respondents who volunteer for a study, whose responses could differ from others;

- Snowball Sampling or Referral Sampling: This form of sampling exists where research participants recruit future subjects from among their acquaintances. Such samples are biased although they could lead to higher response rates.

- Judgmental Sampling or Purposive Sampling: The researchers choose the sample of respondents who they think would be appropriate for their study. This sampling is primarily used when there is a limited number of people that have expertise in the area being researched, or when the research interest is focused on a specific field or a small group. 
A Statistic: This is any quantity calculated from a sample to estimate a population parameter.

A Parameter: This refers to a variable or attribute that is calculated from the population, for example the mean or standard deviation. Good sampling allows large quantitative surveys to represent the views of the population being studied, to a known and calculable degree of accuracy. It is possible, using the correct statistical formulae to find the Level of Confidence and the Limits of Accuracy of a Survey.

- Level of Confidence: This refers to the fact that, from a randomly drawn sample, it is possible to work out the statistical significance. It is very encouraging to hear from researchers, or you may find out from your calculation that you have a $95 \%$ level of confidence in your results.

- Limits of Accuracy: The sample's limit of accuracy can also be calculated. The larger the sample the more accurate the calculation of the populations' parameters are likely to be. That is, the larger the size of the sample, the narrower the range of limits of accuracy.

Reliability in statistics is the overall consistency of a measure. A measure is said to have a high reliability if it produces similar results under consistent conditions.

Validity is a degree of measurement that is equivalent to accuracy. Within validity, the measurement does not always have to be similar, as it does in reliability. However, just because a measure is reliable, it is not necessarily valid. Construct validity refers to the extent to which operationalisations of a construct are measured as defined by theory. Such measures may be associated (convergent validity) or not associated (discriminant validity) with things they should be related with.

The statistical significance suggests that your statistic is reliable and rejects the hypotheses that there is no relationship between two measured phenomena, or no association among groups.

The use of appropriate statistical calculations makes it possible to determine what size of the sample would be required in order to minimise sampling errors. Although it is not essential that marketers are able to perform the statistical calculations; it is important to note that the 
reliability and validity of the findings from large-scale quantitative research surveys is determined by the statistical competence of researchers.

When designing the sample, the researchers should ask themselves three important questions:

- Who is to be surveyed?

- How many people should be surveyed?

- How should the people in the sample be chosen?

- Who is to be surveyed?

It is extremely important to clearly distinguish the aims and objectives of the survey questionnaire; to decide on the sample size, and; the type of survey to conduct. The researchers should clarify what they are looking for. They could carry out some pilot work to ascertain some of the potential issues and difficulties that are related to the data gathering process. Informal discussions and brainstorming sessions provide invaluable contextual knowledge which could give them a clearer picture on the objective and goals of the survey. In this light, original insights may be modified and additional ideas may be brought to the surface. Once the marketers have clearly identified their research objectives, they could decide upon the population they wish to sample.

When deciding the size of their sample; there are a number of questions they must ask. What is the purpose of their survey? What information are they seeking? Are they carrying out a qualitative or quantitative research? What level of accuracy do they require? What level of confidence are they expecting? What time constraints are they working under? How much money is available for research? As already discussed; the level of confidence and of accuracy of a sample may be calculated before the research begins. These factors will greatly affect the size of the sample, and so the researchers will be able to calculate a realistic sample size.

The larger the size of the survey, the greater its precision and reliability. However, practical constraints must be considered; the greater the size of the sample, the greater the cost in terms of labour and money. Careful thought should be given to the time constraint. Urgency will not allow a large survey. Therefore, the validity and accuracy of the project could be put at risk due to short cuts and inadequate samples. The researchers should advise the marketers on the level of accuracy they can expect from small surveys. Cost and accuracy are closely linked, and effective fieldwork is slow and expensive, but it does not always produce reliable and 
accurate results. When size is being considered, the non-response factor should also be taken into consideration.

The selection of a sample relies on the type of sampling method one decides to use. The two basic types of sample are: probability or random samples and non-probability sampling:

\subsubsection{Probability or Random Samples}

These are samples which are constructed so that every member of the population being sampled has an equal chance of being selected. There are a number of ways of selecting a random sample; by using a lottery method, or by using random tables. The purpose of random sampling is to avoid biases which may arise when researchers use their own judgement as they choose samples.

Probability or random sampling has been widely adopted by leading research bodies because they have a sound theoretical basis. As the probability sampling method is based on a mathematical selection of participants, it does not lend itself to bias. The results of a probability sample are statistically-sound unlike other forms of research, namely non-probability sampling. Therefore, the conclusions drawn from surveys responses that were chosen at random are considered to be well-grounded.

However, there are disadvantages to random sampling. In commercial practice, there are very few reliable lists of populations. The population data may be out of date. To construct a sampling frame also takes considerable time and effort. Calls to randomly select informants may be widely scattered, causing considerable costs in time and money. Due to delays in time, the accuracy of the data will be affected. To speed up the process, a larger research team may be employed, which will turn increase the costs of the survey. One of the principle drawbacks of this form of sampling is that non-response is a serious source of bias, so the researcher must endeavour to secure as many successful responses as possible. It is standard practice that, having failed to contact specific respondents by the third attempt, the surveyor may abandon them and should possibly garner the interest of other candidates.

Since random sampling has these drawbacks, it is fairly expensive, when compared to other sampling methods. Nevertheless, researchers believe that the value of random sampling cannot be matched by any other method; in terms of collecting reliable, unbiased information. A trade- 
off has to be made between accurate and statistically reliable results, and considerable costs in time and money.

\subsubsection{Non-Probability Samples}

These are samples that are chosen by the researcher. The selection of the sample is dependent on human judgement, unlike the scientific method of probability sampling. This form of sampling allows the researchers to gather data without sampling, as they dictate who are the respondents. As a result, it is substantially less expensive than random sampling. However, the problem of non-response is minimised. Moreover, the non-probability sampling approach and its data management process is easier, inexpensive and it provides a faster way to gather data; when compared to random sampling. The non-probability method does not necessitate the preparation of sampling frames of special lists of respondents.

Quota sampling is a more refined and accurate version of non-probability sampling. It is a form of judgement sampling; where the biases of non-probability sampling are controlled to some extent by stratification, and the setting of quota in each stratum. The population is divided into sub-groups according to the survey's requirements, for example, by age, gender, social class, et cetera. Quotas are usually set by the researchers and they will select the individual respondents. It is at this stage of the survey where there is potential for bias. However, if the researchers are carefully selected and properly trained, these hazards may be controlled, to some extent. The results from non-probability samples may not be reliable due to possible bias. Hence, the research findings that are derived from these samples are not accurate enough to be extended to the general population.

\subsection{Research - Whose job is it?}

Who should carry out the research is a very valid question. Do the marketing managers have the right skills and competences to do it themselves? Are they assigning an agency to do this job for them? These are basic considerations to take into account when addressing the captioned question.

Can the businesses dedicated sufficient time and resources to carry out the research themselves? The quality of the data to be collected during fieldwork may be threatened if the 
sponsor is identified as the surveyor. Marketing managers are expected to act in an assertive and vocal manner. They can sometimes encounter difficulties in adopting a neutral role, particularly when they are researching the market. However, it is important for managers to engage with customers. The research fieldwork would surely increase their understanding of the market in which they operate. It would also give them a better idea of what to expect from other researchers. It may be possible for the marketing managers to get involved in the fieldwork during the pilot stage of the questionnaire. This will give them a greater appreciation of the strengths and weaknesses of the questionnaire.

Most businesses that are serious about customer-centric marketing will have dedicated market research departments; with at least some skilled and experienced members of staff, who would be capable of gathering and analysing data. For instance, airlines use their own staff to carry out day-to-day market research, including an ongoing flight survey analysis. However, airlines may occasionally recruit external research consultants. External researchers will work in a more objective manner than internal researchers. They will also bring fresh ideas with them. When external research is commissioned, the role of the airlines' managers is to define the research problem. They are expected to specify to the researchers their objectives, and to clarify on the information required. It is crucial that they act on the research results after they have been carefully analysed and processed.

\subsubsection{Preparing a Brief}

The business that is commissioning research should consider a list of specialised agencies which may be appropriate for them. They should choose a reputable research organisation according to its capabilities and expertise. Once a research organisation is chosen, the business should provide a brief to the research organisation, which should include; the business and research objectives; suggestions on how market and consumer data can be collected; the type of research being envisioned (by clearly indicating what are the businesses expectations from this project); question areas to be covered during the research; a realistic time table; and a budget, as featured in Table 2.2. 


\section{Table 2.2 The Research Brief}

Background and research objectives: It is necessary to provide the research organisation with a thorough understanding of the business, its products and services. The researchers have to understand why this research is being carried out. Therefore, the business should provide them with information pertaining to the industry and the marketplace, including existing competition. The business should provide as much information as possible about the characteristics of customers. This will enable the agency to suggest the most appropriate method for contacting the sample. It could also help them to estimate costs more precisely;

Data on the relevant population group: The researchers should be knowledgeable of the business' intention to target a specific population group. They should indicate the segment(s) which should be targeted by the researchers during their fieldwork;

The type of research envisaged: The agency should be informed about what kind of research is required by the business. The business could make use of qualitative or quantitative findings;

Question areas to be covered: An agency will do their job a lot better if the client is specific about what information is required. For example, the business should indicate to the agency; the question areas that should be addressed; and could describe the type of questions that could be used. Of course, this does not mean that the business is designing the questionnaire;

A realistic timetable: The business should indicate the date by which it would like to receive the proposal and also the date by which they need to receive the research findings. This will influence both the type of research method which will be used as well as the planning of the fieldwork;

An invitation to discuss research: This provides the opportunity for the agency to clarify any questions they may have in relation to the project;

Budget: The agency should know how much money the business is budgeting for the research. This way, the research organisation will be in a position to prepare a proposal to meet the businesses' requirements. However, some may argue that, by revealing to the agency that a large amount of money is available, there is a danger that they will find ways to spend the budgeted figures.

It is advisable that the commissioning business will ask for quotes from several research agencies before committing itself with one of them.

\subsubsection{The Research Agency's Proposal}

After the agency has been briefed, the agencies should then return a proposal to the business, by an agreed date. The proposal could include the following elements:

a) Statement of objectives: 
A statement of objectives should clearly reflect the list of objectives that were presented to them, in the brief;

\section{b) Description of how the research will be done}

This includes a description of the various research methods that will be used for data collection. They should give details on the sampling method. A breakdown of questionnaire content should be included, as should details on all the data analytical processes to be undertaken. That is, the coding of data and the statistical analysis of quantitative findings. Alternatively, they could explain how qualitative data will be analysed, et cetera. The agency should justify its decision for adopting specific methodologies;

\section{c) Reporting}

The proposal should highlight how the research findings will be presented. The proposal should give details on the presentation and tabulation of results.

\section{d) Costs}

The agency should also present a clear breakdown of the individual costs for the research project.

\subsection{Implementation of the Research Plan}

Once the management has defined the problem, delineated their research objectives and decided on what information they require, they should proceed to the next stage of the research process. They are expected to design the survey questionnaire and / or prepare a brief for their field interviews.

When the questionnaires have been constructed and tested, it's time for them to start gathering the data. This entails engaging with a sample of respondents, and examining other research options. This process should be closely monitored (by the marketing manager or the research agency, as appropriate) to ensure that the collected data is valid, reliable and trustworthy.

This stage is the most expensive part of the data collection process, and the agency or the organisations' management should continuously monitor how the research is being is carried 
out. The members of staff who are gathering data have be objective whilst collecting their data, throughout the research fieldwork.

\subsection{Data Analysis}

Having collected the data, marketers must then interpret their findings. Interpretation is easier if the data analytical methods are carefully planned in the research process.

The results of the collected data may be a large pile of completed survey questionnaires (if the researchers have used printed questionnaires). Alternatively, the researchers could have annotated their qualitative data in the form of transcripts. The way how the gathered data is analysed and presented is an influential factor of how valuable the research will be. Many research agencies are increasingly using computer software packages to statistically analyse their quantitative findings.

The researchers will draw their own conclusions in writing and may also use data tables. The statistical analyses usually focus on the results, and on what deviates from the variable being measured. These findings will be analysed and interpreted by the researchers, and presented to the respective marketing managers. It is important that they will be in a position to understand the main findings and the research implications.

\subsection{Preparation and Presentation of a Research Report}

The following section provides a useful guideline of what should be featured in a research report. The report will communicate the research findings and the implications of study to the decision makers. Key elements in the report are presented in Table 2.3; 
Table 2.3 Key Elements of a Market Research Report

1) Title Page (This area lists the title, client, research agency, date, et cetera);

2) List of Contents;

3) Preface;

4) Summary of the Findings or Conclusions (the summary of the main findings may be accompanied by recommendations);

Points 1-4 provide a concise report of the nature and outcome of the research programme.

5) Previous Related Research (This section indicates how previous knowledge may have a bearing on the research at hand);

6) Research Method (Procedures that are used to collect information; How was the research conducted? - How was the research carried out? - Who were the research participants? - What were the research techniques that were used in the analysis? The characteristics and size of samples should also be recorded;

7) Results (It is important to provide clear, simple and a logical presentation of the research findings. The results are usually presented through paragraphs, tables and graphs);

8) Conclusions;

9) Appendices.

Points 5-9 provide the detailed evidence from which conclusions, implications and recommendation are derived.

Generally, a report seldom provides answers to all of the research questions under investigation. Thus, the research limitations will have to be pointed out in the report, along with reasonable explanations of the potential weaknesses of the research methodologies, sampling frames and analytical techniques that were employed in the study. Moreover, the research report will only be valuable to the commissioning business it the marketing managers would make a good use of its key findings and recommendations.

\subsection{Questions}

- What are the "needs" and "wants" of business customers?

- In your own words, outline the difference between quantitative and qualitative research.

-Why is non-probability sampling used more frequently than random sampling?

- Outline, in your words, the various steps involved in the market research process. 


\subsection{Summary}

The marketing managers are constantly searching for information which will enable them to make better decisions, and to improve their products or services for the benefit of customers. Therefore, the marketing research will support them in this regard; as its underlying objective is the systematic collection, analysis, interpretation and reporting of information relating to consumers, products and other environmental factors which may influence their organisations' performance.

There are various stages of the market research process. The initial stage is the identification and definition of the problem and research objectives. The second step entails designing the research plan. The researchers may gather primary and / or secondary data. The secondary data can be gathered through a desk research from previous studies and reports. The primary research may be gathered through quantitative and / or qualitative research methods. The quantitative techniques consist of statistical analyses of large numbers of respondents. Qualitative studies are usually carried out on a small sample of research participants. This latter technique will usually involve the investigation of the individuals' in-depth opinions, reactions, beliefs and behaviours. The research fieldwork is the most expensive part of the study. Following the data collection, the researchers are expected to analyse and interpret their findings. The final part of the research process is the preparation and presentation of a report which features key conclusions, limitations of study, research implications and recommendations. 
